\title{
Shape Memory and Superelasticity Editor-in-Chief Honored
}

(c) ASM International 2019

The journal of Shape Memory and Superelasticity is pleased to announce that the Editor-in-Chief, Professor Huseyin Sehitoglu is the winner of the 2020 Khan International Award in the Field of Plasticity.

This award recognizes "outstanding life-long contributions in the field of plasticity primarily through research contributions in all international journals in general and International Journal of Plasticity in particular." This award will be presented at the International Conference on Plasticity, Damage and Fracture 2020 (ICPDF 2020) held January 3-9 in Riviera Maya, Mexico.

Prof. Sehitoglu, who is the John, Alice and Sarah Nyquist Endowed Chair of the Department of Mechanical Science and Engineering at the University of Illinois at Urbana-Champaign, was selected for this award through the citation statistics of his research papers and objective input by the award committee.

In a press release for the award, the University of Illinois, Grainger College of Engineering stated, Sehitoglu "has made important contributions to the plasticity of metals, especially on fatigue - the deterioration and failure of materials in cyclic loadings. He and his students have developed some of the most advanced theoretical models for fatigue crack initiation and fatigue crack growth accounting for the microstructure. Recently, he has worked on an important class of shape memory materials that undergo phase transformations and recover their shape

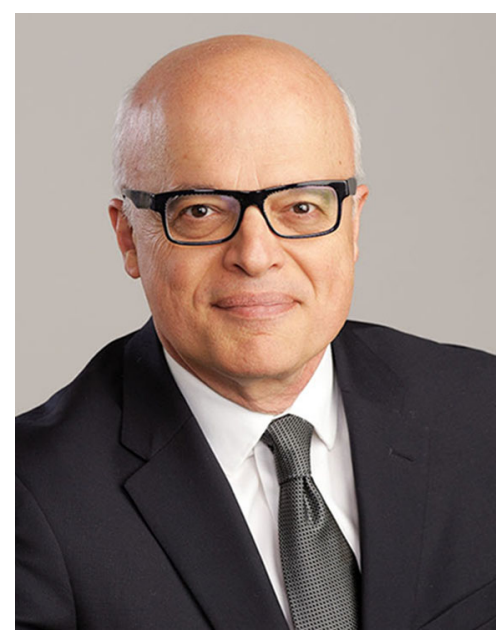

Prof. Huseyin Sehitoglu

upon deformation, and high entropy alloys which exhibit high strength and toughness. He has studied the role of twinning and slip and their interaction in these complex materials."

Congratulations to Professor Sehitoglu.

Publisher's Note Springer Nature remains neutral with regard to jurisdictional claims in published maps and institutional affiliations. 